\title{
VIOLÊNCIA URBANA E PRIVATIZACÃ̃O DO POLICIAMENTO NO BRASIL: uma mistura invisível ${ }^{1}$
}

\author{
Martha Knisely Huggins*
}

\begin{abstract}
Este artigo argumenta que grande parte da violência policial no mundo, em especial no Brasil, tem se tornado invisível, a despeito do caráter público dos homicídios policiais. As ideologias sobre raça e criminalidade ocultam mortes de pobres e negros sob a justificativa de que elas são uma resposta ao aumento do crime entre certos grupos da população. As organizações policiais, mediante operações militares nas favelas, caracterizam essa violência como uma "guerra contra o crime", em que os delinquentes são mais numerosos e armados que os "bons" policiais e cidadãos. A' mistura entre policiamento público e privado torna difícil determinar qual das entidades de controle social provocou essas mortes, particularmente por conta da participação de policiais em serviço e fora de serviço nas empresas de segurança privada. Nesse processo, a segurança tem se convertido em uma mercadoria que separa os pobres dos ricos e os criminosos dos não-criminosos. Apesar de os pobres precisarem mais dos serviços da polícia do que os ricos, eles são percebidos como classes perigosas a serem controladas. Por sua vez, os ricos que podem comprar segurança privada utilizam-na para se proteger daqueles que são vitimizados pela segurança pública.

PALAVRAS-CHAVE: violência policial, tendências do policiamento, centralização, privatização, crise do controle estatal.
\end{abstract}

Na virada do segundo milênio, as atrocidades visivelmente patrocinadas pelo Estado no Brasil podem parecer apenas um pálido reflexo da limpeza étnica e política e outros tipos de violência de grande escala, frequentemente genocidas, em lugares como a Guatemala, Timor Leste, Ruanda, Sudão, Bósnia, Kosovo e na Chechênia. A extensão e o alcance da violência nesses países - com a sua brutalidade crua, seu contexto militar, e com maus tratos e assassinatos de civis pelo Estado e por paramilitares abertamente patrocinados pelo Estado - fazem a violência contemporânea, em tempos de paz no Brasil, ou mesmo durante seus 21 anos (1964-1985) de ditadura militar, parecer muito menos significativa e digna de nota. No entanto, essa suposição sugere a tese questionável de que números mais reduzidos ou um menor percentual de vítimas relativas ao total da população brasileira diminuem a importância dessa situação e de outras semelhantes em

1 Tradução de Perminio Ferreira e revisão de Letícia Azevedo. *Professora Titular no Departamento de Sociologia, Tulane University, New Orleans, LA.

Department of Sociology, Newcomb Hall, 220. New Orleans, LA. 70118 USA. mhuggins12305@yahoo.com que o Estado permitiu ou incentivou a violência. Quer defensável ou não, a validade dessa proposição não pode ser considerada sem serem examinadas a extensão e a natureza da violência no Brasil, onde a violência interpessoal é prevalente e dramática, embora seja disfarçada por ser seletiva quanto à etnia e à classe social e geograficamente concentrada.

Para indicar a extensão da violência no Brasil, somente em São Paulo (a maior cidade da América do Sul), entre 1984 e 1996, houve 69.700 homicídios - superando em mais de 10.000 mortes as baixas sofridas pelos Estados Unidos durante toda a Guerra do Vietnã. Entre 1979 e 1997, a taxa de homicídios no Brasil aumentou de 11,5 para 25,4 homicídios por cem mil habitantes. Esse intervalo de 18 anos estende-se desde os seis anos anteriores à saída dos militares do poder até mais do que doze anos posteriores ao retorno do governo democrático formal. Entre 1979 e 1997, a população do Brasil aumentou $65 \%$, mas a sua taxa de homicídios subiu $120 \%$ (Folha, 1999b, p.3). Em contraste com a taxa de homicídios do Brasil, de 25,4 por cem mil habi- 
tantes em 1997, a taxa de homicídios nos Estados Unidos foi de 10,1 por cem mil habitantes (Internet: www.iabd.org), a qual caiu significativamente, em 1998, para 6,3 (Internet: www.ojp.usdoj.gov/bjs.homicide/hmrt.htm). Com a chegada da década de 1990, a taxa de homicídios do Brasil se aproximou daquela de países recentemente dilacerados por conflitos militarizados internos. Na década de 1990, o Brasil tinha a quinta maior taxa de homicídios no mundo, seguindo a Guatemala, El Salvador, a Colômbia e a Jamaica (Buvinic et al., 1999), sendo esse último também um país sob controle social militarizado.

\section{VIOLÊNCIA SELETIVA}

Embora a taxa geral de homicídios do Bra$\mathrm{sil}^{2}$ seja considerada elevada, quando comparada a taxas internacionais, as taxas de homicídios em muitas localidades e para alguns setores da população são iguais ou até superiores a países latino-americanos ainda envolvidos em guerrilhas internas e conflitos militares. Por exemplo, a Colômbia - formalmente democrática, mas com um conflito militarizado de drogas e guerrilha, com regiões extensas do país sob controle militar, paramilitar ou da guerrilha - teve uma taxa de homicídios no início da década de 1990, de 89,5 homicídios por 100.000 habitantes

${ }^{2}$ As estatísticas de homicídios variam radicalmente no Brasil, com várias agências citando estatísticas diferentes para a mesma cidade ou região. Neste estudo, utilizei as estatísticas mais comumente citadas pela fonte mais confiável. A maioria das fontes se baseia em estatísticas da polícia, mas algumas estatísticas foram obtidas com maior cuidado do que outras, a partir de registros policiais. Muitos sabem, no Brasil, que a polícia pode não ser uma fonte confiável de estatísticas sobre homicídios. Devido ao seu envolvimento em assassinatos (ver Nota 8), a polícia pode documentá-los erroneamente ou simplesmente não documentá-los. As provas periciais necessárias para estabelecer o envolvimento da polícia em um assassinato também podem ser destruídas, como, por exemplo, no caso de dúvida entre ser o homicídio uma execução ou uma troca de tiros. A polícia pode facilmente distorcer as provas de seus crimes, porque, em muitas cidades brasileiras, a Polícia Civil controla os necrotérios (Instituto Médico-Legal). Essas situações de registro e notificação de homicídios pela polícia resultam em subnotificação, um problema que alguns pesquisadores corrigiram pelo exame cuidadoso dos registros de homicídios da polícia e pelo trabalho em necrotérios (Cano, 1997).
(Buvinic et al., 1999), o que é claramente superior à taxa geral do Brasil em 1997, de 25,4 (NEV, 2000). No entanto, a taxa geral de homicídios foi menor do que as da cidade de Diadema, na Grande São Paulo, em 1998 (140), impactada pela reestruturação da indústria automobilística e permanência da pobreza, e do distrito pobre de Embu $(97,32)$ (Folha, 1999b, p.3). A taxa da Colômbia também foi menor do que as de Recife (105), no Nordeste empobrecido do Brasil, e Vitória (103), no estado do Espírito Santo (NEV, 2000). Com efeito, a taxa de homicídios em Diadema está hoje mais próxima das taxas de homicídio da Guatemala e de El Salvador (150) do final dos anos 1980 (Buvinic et al., 1999), quando esses países estavam enfrentando uma intensa guerrilha interna e conflitos de contrainsurgência.

O padrão de violência urbana do Brasil é claramente mais dramático em algumas regiões e para segmentos da população. Em 1997, as duas maiores cidades do país, Rio de Janeiro e São Paulo, ficaram em terceiro e quarto lugares, depois de Recife e Vitória, com 65,8 e 56,7 homicídios por 100.000 habitantes, respectivamente (NEV, 2000). No entanto, dentro das cidades do Brasil com taxas de homicídios elevadas, os assassinatos são mais comuns nas áreas mais pobres. Por exemplo, em 1997, o município de Belford Roxo, na região metropolitana do Rio de Janeiro, com uma população que varia da classe operária até a pobreza extrema, teve 73 homicídios por 100.000 habitantes, mais de 10\% superior à taxa geral da cidade do Rio. Em 1998, o município de Diadema, na Grande São Paulo, teve 140 homicídios por 100.000 habitantes, e a taxa de homicídio de Embu foi de 97,3; em ambos os municípios, as taxas de homicídios foram muito maiores do que a taxa global da cidade de São Paulo, de 56,7 (Folha, 1999c, p.3). No Morumbi, bairro de São Paulo, seus moradores miseráveis têm 18 vezes mais chance de serem assassinados do que os seus concidadãos no bairro Jardim Paulista, mais próspero e menos acentuadamente estratificado (Estado, 1997, C4). Claramente, as taxas de homicídio nos bairros pobres são nitidamente mais ele- 
vadas do que nos bairros mais abastados, e maiores do que as taxas de homicídio gerais da cidade de São Paulo e do Brasil.

Além disso, nem todos os brasileiros - mesmo nessas cidades e bairros violentos - têm a mesma probabilidade de ser assassinados. Entre as vítimas da violência no Brasil, os negros pobres do sexo masculino são os mais vulneráveis. Esse padrão racial se verifica igualmente nos Estados Unidos, onde os negros têm seis vezes mais probabilidade de ser assassinados do que os brancos (Internet: www.ojp.usdoj.gov/homicide/race.htm). No Brasil, dentro da concentração racial dos homicídios, os jovens - em sua maioria do sexo masculino - com idade entre 15 e 24 anos têm sete vezes mais chance de ser assassinados do que todos os outros grupos etários juntos, de ambos os sexos. É especialmente arriscado ser um jovem do sexo masculino ${ }^{3}$ em cidades brasileiras como Vitória, onde a taxa de homicídio de jovens é de 169,5 por 100.000 habitantes - mais de 500\% superior à taxa geral da população brasileira (Folha, 1998c, p.3). Em Recife, a taxa de homicídios juvenis é 207,7, ao passo que a taxa global da cidade é 105,3. No Rio de Janeiro, as taxas de homicídio juvenil são de 190,2, e, em São Paulo, 155,5; as taxas de homicídios de jovens de cada cidade são quase $200 \%$ maiores do que as suas taxas globais (1998c). Em contrapartida, a taxa de homicídios em 1997, nos Estados Unidos, na faixa etária de 15 a 19 anos, foi de 22,6 por 100.000 habitantes (Internet: www.cdc.gov). ${ }^{4}$ Até mesmo os estados com maiores taxas de homicídio de jovens nos Estados Unidos-Illinois (50,8), Nevada (44,3), Louisiana $(42,4)$ e Maryland (36,5) (Internet: www.usdoj.gov:80/bjs/ pub/pdf/tjv97up.pdf) - apresentavam taxas menores que os da metade das taxas mais altas de homicídio de jovens das cidades e estados brasileiros.

\footnotetext{
${ }^{3}$ Historicamente, a polícia brasileira não costumava registrar a cor das vítimas; quando registrava, era pouco provável que divulgasse essas informações. Dados mais recentes registram a cor das vítimas.

${ }^{4}$ A taxa de homicídios nos Estados Unidos, em 1994, para homens não-brancos foi de 50 óbitos por 100.000 habitantes; para os homens brancos foi de 9,6. Para mulheres não-brancas e brancas, as taxas de homicídio foram 14,2 e 3,5 , respectivamente (Internet: www.cdc.gov).
}

\section{CONTROLE SOCIAL}

Complementando a hipótese de que as altas taxas de homicídio no Brasil são tornadas invisíveis porque as vítimas vêm principalmente de setores já marginalizados da população brasileira, argumentamos que o status da maioria dos agentes de homicídio também ajuda a mascarar essa violência letal. Para analisar a violência em países em desenvolvimento econômico (ou mesmo em países desenvolvidos), com instituições formalmente democráticas, é necessário reconhecer que esse estudo não pode ficar limitado ao sistema oficial de controle social, representado por leis, tribunais e polícia, mas precisa considerar outros aspectos que compõem o sistema de controle repressivo desses países. No Brasil, por exemplo, além do sistema oficial de controle social da população, é preciso levar em conta dois processos institucionais aparentemente contraditórios. Por um lado, a centralização e militarização da polícia profissional, e, por outro, a privatização e a descentralização do controle social repressivo. Enquanto uma parte do sistema de controle social tornou-se mais centralmente controlada e militarmente organizada - exemplificando o que Davis (1992, p.244-257) chama de fenômeno Robocop - outra parte tem se tornado cada vez mais mercantilizada e voltada contra a população considerada problemática. Cada processo contribui de forma distinta para mascarar o papel do Estado na repressão.

Considerando os altos níveis de violência no Brasil, qual o papel dos agentes formais de controle social? Olhando a violência policial no Brasil, ${ }^{5}$ o especialista em polícia Paul Chevigny (1996) afirma que, já em período avançado do seu processo de redemocratização, a maior democracia formal da América Latina, o Brasil, teve um dos piores registros de violência policial ur-

${ }^{5}$ As duas principais forças policiais do Brasil são a Polícia Civil e a Polícia Militar. Neste estudo, a Polícia Militar é chamada de polícia militarizada, para distingui-la da Polícia Militar do Exército Americano. Embora a Polícia Militar tenha sido (junto com a Polícia Civil) subordinada ao Exército durante o período militar no Brasil (1964-1985), hoje ela tem com ele apenas vínculos mínimos, enquanto a Polícia Civil não tem vínculo algum. 
bana das Américas. Em 1992, apenas na região metropolitana de São Paulo, a polícia matou 1.470 civis - quase quatro vezes mais do que o número total desse tipo de morte durante um intervalo de 15 anos dentro dos 21 anos de ditadura militar do Brasil (Reuters, 1997). Apesar de essa violência ter diminuído em 1993 para pouco menos de 300 assassinatos de cidadãos cometidos pela polícia anualmente, na região metropolitana de São Paulo, a incidência aumentou para 430 em 1998 e para 498 em 1999. No Rio, esses homicídios praticamente dobraram entre 1997 e 1998, com 430 cidadãos mortos pela polícia em 1998 - cerca de 38 assassinatos por mês. Como a população do Rio de Janeiro é menor que a metade da população de São Paulo, a taxa de letalidade da força policial do Rio foi, pelo menos, duas vezes mais elevada do que a de São Paulo (Cano, 1997, p.19). ${ }^{6}$

Comparemos as mortes de cidadãos pela polícia brasileira com situações semelhantes em duas grandes cidades dos Estados Unidos, Los Angeles e Nova Iorque, onde policiais foram recentemente acusados de violência e corrupção. Em Los Angeles, o número médio anual de assassinatos de cidadãos cometidos pela polícia, entre 1985 e 1989, foi de 25, enquanto, em Nova Iorque, a média anual nesse período foi de 23 (New York Times, 2000, B1; Kocieniewski, 1998, B1). Entre 1989 e 1992, em Washington, os assassinatos de cidadãos cometidos pela polícia variaram anualmente entre quatro (1989) e sete (1990 e 1992), aumentando para 16 em 1995 e, em seguida, diminuindo abruptamente para seis em 1996 (Leen et al., 1998, p.A1).7 Ainda em 1996, em Nova Iorque, a polícia matou 31 cidadãos, o que diminuiu para 19 em 1998 e para 11 em 1999 (New York Times, 2000, B1). Levando em conta a taxa média anual de mortes de civis

${ }^{6}$ Diz-se que Washington, nos Estados Unidos, tem a maior taxa per capita de assassinato de cidadãos pela polícia (Lean et al. 1998, A1).

${ }^{7}$ O Secretário de Segurança Pública do Rio de Janeiro, Nilton Cerqueira, que tomou posse em Maio de 1995, instituiu o pagamento de prêmios para os policiais envolvidos em confrontos armados ("atos de bravura”) com supostos criminosos. Durante seu funcionamento, essa política (apelidada por seus opositores de "Premiação Velho Oeste") pelas polícias de Washington e de Nova Iorque. ${ }^{8}$ seriam necessários cerca de 50 anos em Washington e 25 anos em Nova Iorque para a polícia assassinar tantos cidadãos quanto aqueles mortos por policiais em São Paulo, apenas no ano de 1999. A polícia do Rio mata tantos civis anualmente quanto o conjunto das forças policiais dos Estados Unidos, embora a população do Rio de Janeiro seja de 5,5 milhões e a dos Estados Unidos de mais de 250 milhões (Cano, 1997, p.19).

Com base em uma razão de "letalidade", de óbitos de cidadãos devido a ferimentos, Cano defende que, no Rio de Janeiro, a taxa de mortes por ferimentos está mais próxima dos países com taxas de belicosidade de guerra do que de operações de controle social em tempos de paz. O desfecho da força letal da polícia no Rio de Janeiro sugere que a ela tem por objetivo matar os suspeitos e não apenas feri-los. Como Paul Chevigny (1996) argumentou, "Se a polícia mata mais do que fere, ou se a precisão dos seus tiros começa a aumentar repentinamente, isso sugere que os tiros letais podem ser disparados deliberadamente." Efetivamente, Cano (1997) mostra que aproximadamente $70 \%$ das pessoas atingidas por tiros da polícia do Rio morrem - um "índice de letalidade" de 2,3 para 1 (942 mortos e 410 feridos), contrastando com uma taxa nas cidades dos Estados Unidos de menos de um para um. No entanto, o uso de força letal pela polícia, no Brasil, assim como as taxas de homicídio, não estão distribuídas uniformemente. ${ }^{9}$ A vítima mais comum dos tiros disparados pela polícia em São Paulo é jovem: 70\% dos baleados têm entre 18 e 25 anos, 97\% são do sexo masculino,

dobrou o número de homicídios de cidadãos pela polícia (Folha, 1999e, p.3-6; Cano, 1997, p.24-25). A administração subsequente da polícia instituiu uma política de concessão de bônus para esquadrões inteiros de polícia para reduzir os homicídios, e o número de assassinatos de cidadãos pela polícia caiu (Folha 1999f, p.3-6).

${ }^{3}$ Esses números foram obtidos pela soma de assassinatos de cidadãos pela polícia ao longo de três anos em Washington, e três anos na cidade de Nova Iorque, seguido pela divisão desse valor pelo número de anos. Isso resultou em 10 assassinatos por ano para Washington e 20 para a cidade de Nova Iorque.

Homicídios de cidadãos pela polícia podem representar de um quarto até metade de todos os homicídios conhecidos em algumas grandes cidades brasileiras. 
$62 \%$ são negros, e, em sua maioria, são pobres e sem antecedentes criminais conhecidos (Folha, 1999d, p.3-4). No Rio, as mortes de cidadãos são mais prováveis nas favelas do que em áreas nãofaveladas. Em termos mais específicos, no fim dos anos 1990, os homicídios de cidadãos pela atuação policial no Rio de Janeiro foram seis vezes maiores nas áreas de favelas do que em bairros não-favelados, e os tiros de policiais nas favelas foram significativamente mais letais do que em áreas não-faveladas (Cano, 1997, p.37). Como exemplo, o resultado fatal de disparos da polícia em favelas do Rio foi mais do que duas vezes superior àquele de áreas não-faveladas.

A grande maioria dos assassinatos de cidadãos pela polícia brasileira ultrapassa até mesmo a violência de "atirar para matar" do assassinato de Amadou Diallo por quatro policiais de Nova Iorque, em 1999. Usando os relatórios de autópsia do Rio de Janeiro, Cano mostra que, em pelo menos metade dos assassinatos em favelas, a vítima tinha quatro ou mais ferimentos à bala, principalmente nos ombros, no tórax e na cabeça. As vítimas do uso de força letal pela polícia no Rio foram atingidas pelas costas em $65 \%$ das vezes, sugerindo que elas foram alvejadas quando fugiam, e não em confronto com a polícia (1997, p.43). Se as mortes desses cidadãos fossem o resultado de tiroteios em favelas entre a polícia e criminosos fortemente armados, como é alegado frequentemente pelos policiais brasileiros, elas deveriam ter sido acompanhados por altas taxas de mortes de policiais. No entanto, as mortes de policiais no Rio são mais frequentes em áreas não-faveladas do que em favelas. Em áreas não-faveladas, um policial do Rio morre em cada 35 tiroteios de força letal, enquanto, em favelas, a relação é de um policial morto para cada 75 tiroteios policiais (Cano, 1997, p.37). No geral, os policiais do Rio têm oito vezes mais chance de matar os pretensos perpetradores do que serem mortos (1997, p.22). Uma pesquisa do Instituto de Estudos Religiosos do Rio divulga que até um quarto dos assassinatos de cidadãos por policiais nessa cidade foi re- sultante de execução: depois de imobilizar a vítima, a polícia matou a pessoa à queima-roupa (Departamento de Estado dos Estados Unidos, 1999). Exames periciais dos assassinatos de cidadãos pela polícia de São Paulo demonstram que uma em cada 10 mortes tinha características de execução (Folha, 1998d, p.3-11).

\section{PERCEPÇÕES DE LEGITIMIDADE E JUSTIFI- CATIVAS PARAAINVISIBILIDADE}

Apesar da natureza potencialmente pública dos assassinatos de cidadãos pela polícia, várias pesquisas sociológicas mostram que pessoas aleatoriamente entrevistadas em 10 capitais brasileiras usualmente não consideram a violência policial como a mais séria ameaça à sua segurança; elas veem a violência dos "bandidos" e a violência interpessoal entre os cidadãos, comumente relacionada a drogas e gangues, como mais graves (Cardia, 1999, p.28-29). Ao mesmo tempo, os brasileiros também não aprovam muito a ação da polícia. Em 1997, em São Paulo, um em cada quatro moradores entrevistados aleatoriamente afirmou ter mais medo da polícia do que de criminosos comuns, e outro terço acreditava que a polícia e criminosos comuns são igualmente perigosos (Reuters, 1997). No entanto, 25 a 40\% dos entrevistados em 10 capitais brasileiras acreditam que a polícia deveria ter o direito de parar e revistar pessoas suspeitas de ilegalidade, apesar de apenas 8 a $27 \%$ acharem que a polícia tem o direito de atirar em um suspeito armado (Cardia, 1999, p.90-91).

Esses resultados contraditórios levantam duas questões relacionadas com a violência policial: Por que há tão pouco clamor público quanto a assassinatos de cidadãos, quando a polícia brasileira mata tanta gente ${ }^{10}$ Por que esses assassinatos

${ }^{10}$ Uma exceção notável para o fracasso dos brasileiros em protestar contra a brutalidade policial aconteceu no início de abril de 1997, depois do principal canal de TV no Brasil, a TV Globo, exibir cenas secretamente gravadas na favela Naval em Diadema, que mostravam a polícia humilhando, batendo, torturando e extorquindo dinheiro da- 
resultam em tão pouca ação política e indignação moral, uma vez que a polícia brasileira é tão mal vista? No nível macroteórico, a resposta incorpora as percepções dos cidadãos quanto às vítimas da violência, a suposição de vítimas criminosas, a imagem de crime, e a missão de guerra contra o crime da polícia brasileira. As vítimas de homicídios, principalmente da classe menos economicamente favorecida no Brasil, são consideradas pelo público brasileiro e pela polícia como intrinsecamente "marginais" e socialmente nocivas; os lugares onde vivem (em favelas ou nas ruas) são vistos como "poluídos" e perigosos; a sua presença fora das favelas é considerada socialmente inadmissível (Caldeira, 1992; Huggins; Mesquita, 1995; ScheperHughes; Hoffman, 1994). Portanto, em lugar de ver essas pessoas assassinadas como "vítimas", elas são consideradas "perpetradoras", cujo comportamento perigosamente "mau" deve ser violentamente gerenciado para proteger os cidadãos "de bem”. Como supostos "criminosos", a violência contra ou entre esses segmentos da população brasileira é tornada invisível por uma ideologia que transforma as vítimas em "outros" deslegitimados, que devem ser controlados em benefício de interesses especiais "legítimos".

Assim, enquanto a militarização centralizada do policiamento deveria, teoricamente, tornar o controle social patrocinado pelo Estado mais óbvio, no Brasil, essa militarização reduziu significativamente a visibilidade das políticas estatais repressivas, por meio das ideologias da "guerra contra o crime" e "profissionalismo" da polícia, que se justificam e se reforçam mutuamente. A primeira permite que os formuladores de políticas e o público definam o crime e os "outros" desviantes como externos à ação política "legítima”, justificando a extensa e violenta repressão pelo Estado ${ }^{11}$ como socialmente necessária e mo-

queles que prenderam. As cenas explícitas de violência policial alimentaram a impaciência crescente dos brasileiros com a impunidade da polícia, embora muito pouco tenha sido feito contra os policiais envolvidos. Como exemplo, dois dos policiais envolvidos foram presos, mas libertados quatro dias depois.

${ }^{11}$ Os militares brasileiros ocuparam favelas do Rio de Janeiro nos últimos anos, mas têm sido relutantes em fazê-lo, preferindo deixar a Polícia Militar realizar as "blitze". ralmente inatacável, sobretudo quando ordenada ou realizada pela polícia. Por sua vez, a ideologia do "profissionalismo" policial modernizado e racional transforma os policiais em "profissionais" treinados e qualificados, com ampla liberdade para decidir por si mesmos quando e como usar a violência letal para derrotar um "inimigo" generalizado na guerra militarizada contra o crime. Quando essa guerra resulta em mortes de cidadãos, esses assassinatos são apresentados como o resultado inevitável da legítima defesa da polícia contra "criminosos perigosos".

\section{PRIVATIZANDOEOCULTANDOASSASSINATOS}

Outro componente essencial para a compreensão da relativa invisibilidade moral e política da extrema violência pública no Brasil é a condição mista dos seus agentes - uma combinação de policiais em serviço, vigilantes privados e justiceiros individuais e em grupo. No Brasil, a privatização do controle social surgiu para proteger uma população de "verdadeiros cidadãos", cada vez mais segmentada, isolada e "cercada" socialmente, daqueles contingentes marginalizados e deslegitimados como "criminosos perigosos", uma designação que reforça o status desses últimos como não-cidadãos. Nesse sistema privatizado, tanto os supostos criminosos quanto os agentes de seu controle social são segregados, primeiro, em grupos especiais de "outros" deslegitimados, que devem ser controlados para o bem dos interesses especiais legítimos e, segundo, em diferentes tipos de agentes pagos por segmentos privilegiados da população para servir a seus interesses particulares.

O fato de uma parte das mortes de cidadãos ser privatizada no Brasil oculta preocupações morais e políticas quanto ao controle social violento. Os assassinatos são realizados por policiais fora de serviço e em serviço, sob contrato com empresas particulares e moradores, ou por esquadrões da morte e "justiceiros" contratados para matar; os dois últimos, por vezes, com a 
participação de policiais ou com conexões com eles. $\mathrm{O}$ fato de as forças policiais privatizarem a sua própria violência é ilustrado pelo aumento de assassinatos dos cidadãos por policiais fora de serviço. Por exemplo, em São Paulo, durante os últimos três meses de 1999, dos 109 cidadãos mortos pela Polícia Militar, 63\% (69) foram mortos por policiais fora de serviço, enquanto trabalhavam como vigilantes privados - um aumento de $82 \%$ em relação a 1998. A Polícia Civil de São Paulo, que geralmente mata por ano menos cidadãos do que a Polícia Militar, assassinou 24 cidadãos no último trimestre de 1999, metade dos quais foi morta por policiais civis fora de serviço - um aumento de $140 \%$ em relação ao mesmo período de 1998 (Folha, 1999e, p.3-11).

\section{O CONTINUUM DA REPRESSÃO}

A outra razão que contribui para a invisibilidade da violência letal no Brasil é a falta de fronteiras claras entre o policiamento público e o "vigilantismo" informal dos cidadãos. Trata-se de modalidades de controle social e categorias de agentes que, em muitos aspectos, estão misturadas tanto em termos organizacionais quanto perceptivos. Por exemplo, entre meados e final da década de 1970, um esquadrão da morte do Rio de Janeiro foi chefiado por um ex-policial militar, Silas Pereira de Andrade, conhecido popularmente como "Sargento Bob." Esse esquadrão da morte era financiado pelo proprietário de uma cadeia de supermercados do Rio de Janeiro, Antônio Sartorio Filho, que pagava 1.600 cruzeiros (então equivalentes a 107 dólares americanos) mensalmente para o sargento Bob coordenar a segurança dos seus estabelecimentos. Cada um dos 15 homens desse esquadrão da morte - que incluía policiais comuns fora de serviço do XX Batalhão de Polícia Militar - recebia 350 cruzeiros semanalmente (então, cerca de 24 dólares americanos) por seu trabalho. Tal esquadrão da morte operava com um contrato semanal de longo prazo com a cadeia de supermerca- dos, como uma empresa clandestina de segurança privada contra roubo e furto (Huggins, 2000, p.218-219). Outros esquadrões da morte que atuavam no Rio, na época, agiam mais como equipes free-lance de assassinos (rent-a-hit) vendendo-se um assassinato por vez para o melhor pagador privado. Apesar das diferenças entre os dois graus de privatização, ambos os esquadrões da morte incorporavam policiais fora de serviço em sua estrutura de trabalho.

A característica definidora do controle social privatizado no Brasil é de que ele se desenvolveu, de um modo geral, a partir da organização formal da polícia, com a qual segue mantendo uma ligação permanente. Dado o papel decisivo da organização policial na privatização do controle social no Brasil, é pertinente situar esse controle em um continuum (Huggins, 1991) que compreende desde policiais em serviço, no polo mais formal, a justiceiros e grupos de linchadores, no polo mais informal. O intervalo do meio do continuum, por sua vez, é preenchido por vários mecanismos, privados e públicos, de controle social: policiais em serviço subcontratados para vigiar edifícios e estabelecimentos públicos ou privados, policiais em serviço que são donos de empresas de segurança privada, empresas de segurança privada (rent-a-cop), regulamentadas ou clandestinas, que operam com força de trabalho policial e esquadrões da morte. Como o exemplo anterior de esquadrões da morte ilustra, as entidades públicas e privadas de controle social se assemelham a empresas de segurança privada e esquadrões da morte (com policiais fora e em serviço), misturando-se e desenvolvendo uma comunhão de filiação e fidelidade a interesses particulares que predominam sobre os interesses públicos, assim como são avessas à supervisão e ao controle aberto e direto do Estado e da população. Consequentemente, verifica-se um fluxo facilitado de policiais dentro e fora das empresas de segurança e dos esquadrões da morte, o que evidencia a diluição dos limites reais entre essas entidades de controle social, como ilustra o exemplo que se segue. 
O surgimento dos esquadrões da morte modernos, no Brasil, data de 1958, quando o chefe das forças policiais da então Capital Federal do Rio de Janeiro, General do Exército Amaury Kruel, foi pressionado pela Associação Comercial do Rio de Janeiro para fazer algo quanto aos furtos e roubos que afetavam seus negócios. Kruel ordenou que seu Delegado Chefe, Cecil Borer, montasse um grupo semissecreto de policiais especiais, o Serviço de Diligência Especial, sob a chefia do Inspetor da Polícia Civil Milton Le Cocq de Oliveira, um policial que havia começado sua carreira na Polícia Militar e, mais tarde, transferiu-se para a Polícia Civil. O novo esquadrão de Le Cocq era formado pelos policiais considerados "mais corajosos", que declararam aceitar morrer em perseguição aos bandidos do Rio de Janeiro. Daí a origem de sua marca popular: homens corajosos (Huggins, 2000, p.207).

Os "caçadores de bandidos" de Kruel estavam organizados em uma unidade especial motorizada de patrulha - o Esquadrão Motorizado - dentro da Polícia Civil, e, portanto, não eram externos à organização da polícia. Popularmente chamado de "E.M.", o grupo de Kruel tinha a missão explícita de matar "criminosos perigosos" por sua própria iniciativa. A revista Time (1969, p.61) relatou, em 1969, que, nos 11 anos anteriores, essa unidade policial assassinou uma média de uma pessoa por semana, o que foi comprovado pela revista Veja que, à época, era censurada pelos militares (1970a, p.31). Apesar da negação posterior por Kruel de que a sua unidade teria sido um esquadrão da morte - ele disse que teria "apenas ordenado sua polícia a não morrer, a matar" -, esse grupo policial rapidamente tornou-se o que mais tarde foi acusado de ser: um esquadrão da morte.

Como prova da facilidade com que os esquadróes da morte geram outros, o mesmo inspetor Le Cocq montou, em 1958, um Esquadrão de Morte paralelo, com oito homens, cuja sigla também era “E.M.”. Esse grupo foi informalmente batizado de "turma da pesada", para indicar a vontade ainda maior de seus membros de "arris- car suas vidas perseguindo pistoleiros" ou criminosos armados. Para isso, o grupo recebia uma remuneração adicional e "por fora" de empresas e representantes da justiça para trabalhar como vigilantes (rent-a-cops) de estabelecimentos comerciais (Veja, 1970b). Nas favelas, valas e campos do Rio de Janeiro, os corpos dos mortos que começaram a proliferar tinham sinais de tortura e a marca do esquadrão da morte, entalhados nos corpos, uma caveira e ossos cruzados. Notas assinadas "E.M." eram presas aos corpos das vítimas afirmando: "Eu era um ladrão", "Eu vendia drogas", ou "Eu era um criminoso" (Langguth, 1978, p.121). Os assassinatos eram comumente publicados no dia seguinte, no boletim interno do Departamento de Segurança Pública do Estado do Rio, incluindo o dinheiro pago por cada assassinato (Jornal do Brasil, 1975), sugerindo a relação aberta entre os esquadrões da morte contratados e a organização da polícia. Os homicídios também eram divulgados na rádio pelo encarregado de "relações públicas" do esquadrão da morte, Ivo Americano Alves Brito, que, antes de entrar no E.M. informal do Rio de Janeiro, havia sido um agente de segurança da Polícia Federal no Itamaraty, Ministério das Relações Exteriores do Brasil (Huggins, 2000).

\section{PRIVATIZAÇÃO E MERCANTILIZAÇÃO DA SEGURANÇA}

No Brasil de hoje, os esquadrões da morte continuam a funcionar, paralelos a uma crescente indústria de segurança privada, com cada entidade de controle social servindo diretamente a diferentes segmentos da população e buscando beneficiar um em detrimento do outro. Os pobres são indiferentemente tratados como "criminosos" pelos esquadrões da morte e empresas de segurança, e os brasileiros mais ricos são protegidos dos pobres por suas forças de segurança privada. Um alicerce importante no Brasil para o surgimento dessa segurança privatizada é a insegurança socialmente estratificada. Em um país 
onde os serviços do Estado são alocados e desfrutados de acordo com o "grau de cidadania" política e econômica dos membros da população, aqueles que são definidos como não-cidadãos podem esperar pouca ou nenhuma proteção do Estado. Por exemplo, os municípios pobres da Grande Rio de Belford Roxo, Nilópolis, São João de Meriti e Nova Iguaçu têm um policial para cada 2.000 habitantes, enquanto que, em Copacabana e Leme, bairros de classe média do Rio de Janeiro, há sete policiais para cada 2.000 habitantes (Folha, 1999f, p.3-6). Além de os bairros mais ricos terem mais policiamento público - embora os brasileiros mais ricos ainda considerem o número insuficiente -, eles também contratam seguranças particulares para proteger seus espaços sociais contra o ingresso ou a presença "ilegítima" daqueles que são vistos como "não-cidadãos". Em contraste com isso, enquanto os "não-cidadãos" pobres raramente são protegidos pelo sistema de controle social estatal, eles aprenderam a esperar incursões rápidas, violentas e periódicas da Polícia Militar em suas favelas, entremeadas regularmente por assassinatos cometidos por esquadrões da morte, justiceiros solitários e grupos de linchadores.

Essa estrutura de controle social formada pela polícia, por empresas de segurança, esquadrões da morte, justiceiros e grupos de linchadores sugere um mundo não mais perfeitamente divisível entre, por um lado, espaços públicos e privados e, por outro, entre policiamento público e privado (Bayley; Shearing, 1996). Além da propriedade pública e privada, existe agora um estado intermediário que Shearing e Stenning (1983, p.496) denominam de "propriedade privada de massa" (mass private property), em que atividades públicas ocorrem dentro de instalações privadas que são primariamente protegidas pela segurança privada apoiada pela polícia.

Com a globalização do capital e a expansão de novas indústrias, espaços de lazer e modos de vida, o Brasil, a exemplo de outros países, vem conhecendo uma expansão dramática das propriedades privadas de massa e das em- presas de segurança privada que trabalham para elas. Embora calcular o tamanho da indústria de segurança privada no Brasil seja difícil, o sindicato de vigilantes privados do estado de São Paulo, SESVESP (2000), informa a existência de 400 mil seguranças privados regulamentados no Brasil. Para ser registrado, o vigilante (98\% são do sexo masculino) deve ter 21 anos ou mais, possuir pelo menos o ensino fundamental, passar por exames psicológicos e físicos básicos, realizar curso de formação de 120 horas e ser registrado na Polícia Federal do Brasil. Esse registro começou sistematicamente em 1983, 16 anos após o governo federal do Brasil (na época militar) ter concedido às empresas de segurança privada nacionais ${ }^{12} \mathrm{O}$ direito de operar no Brasil. Sentindo-se incapaz de controlar os roubos a bancos, sobretudo os politicamente motivados, o governo militar brasileiro instituiu, em 1967, a proteção de segurança privada para empresas financeiras e agências governamentais. Apesar de a legislação limitar o número máximo de empresas de segurança de capital nacional em cada estado - o estado de São Paulo, por exemplo, não poderia ter mais do que 50 empresas de segurança privada (SESVESP, 2000) -, o número das empresas de capital brasileiro cresceu dramaticamente por conta do aumento das ameaças percebidas ao comércio e à segurança pessoal, do setor de seguros para proteção a essas ameaças e da propriedade privada de massa residencial, comercial ou de lazer. Assim, só no estado de São Paulo existem, hoje, 310 empresas regulamentadas e pelo menos mais 300 clandestinas (2000).

Entre os tipos de conflito potenciais que podem ser gerados pela indústria de segurança privada do Brasil, podem ser apontados dois: a) entre o governo e as empresas de segurança quanto à lealdade do pessoal de segurança privada, e o controle do governo sobre a própria segurança pública; b) entre empresas de segurança e seus

${ }^{12} \mathrm{Na}$ regulamentação inicial das empresas de segurança privada pelo governo brasileiro (1967), empresas de segurança internacionais foram proibidas de operar no Brasil, o que ainda está em vigor. Contudo, já existem parcerias não-oficiais entre empresas nacionais e internacionais. 
clientes, quanto à entidade que receberá lealdade primária. Embora pouco tenha sido escrito sobre esse processo no Brasil, há alguma lembrança (2000.) de que a regulamentação das empresas de segurança privada no Brasil resultou do malestar do governo militar brasileiro quanto ao potencial "paramilitar" dessas empresas - um pensamento aparentemente inquietante em 1967, quando o governo militar no Brasil travava uma guerra interna contra a subversão representada pelas guerrilhas paramilitares. Em 1983, o governo brasileiro chegou a uma difícil situação, quando funcionários da segurança interna do governo ouviram relatos de que vigilantes, em algumas cidades, viam-se primeiramente como funcionários de sua empresa de segurança e, secundariamente, como trabalhadores dos estabelecimentos que os contrataram para se proteger. Outro problema igualmente urgente era o das lealdades conflitantes, que contrapunham, por vezes, os vigilantes e os funcionários e leis municipais, estaduais ou federais. A resposta do governo central brasileiro foi colocar a segurança privada sob seu controle rígido, com o aprimoramento ("profissionalização") dos serviços de segurança privada, mediante o registro das empresas e de seus funcionários na Polícia Federal (2000), reforçando, desse modo, o controle sobre eles.

Apesar dessas mudanças, ou talvez em

${ }^{13}$ Há, pelo menos, três vezes mais vigilantes no Brasil do que soldados no serviço militar (SEJUP, 1996; SESVESP, 2000).
Brasil seja difícil de estimar, em 1985, o país tinha três vezes mais policiais do que vigilantes regulamentados. Em 1999, a proporção havia se invertido, com três vezes mais vigilantes regulamentados do que policiais. A proporção se mantinha na maioria dos estados grandes e importantes. Por exemplo, em 1999, o Estado de São Paulo tinha 100 mil vigilantes regulamentados ${ }^{14}$ (SESVESP, 2000), ou quase três vezes mais vigilantes do que o total de efetivos das Polícias Civil e Militar do estado.

Em 1998, a indústria de segurança privada do Brasil faturou 4,5 bilhões de dólares americanos (2000) ou 1,1 bilhões de dólares a mais que a Pinkertons, a empresa de segurança com maior receita nos Estados Unidos, com faturamento anual de US \$ 3,5 bilhões em 1998 (Johnson, 2000, 4-A). O faturamento de todas as empresas de segurança privada americanas, naquele ano, foi de 90 a 100 bilhões de dólares (Schorr, 1999, p.11), ou 20 vezes mais do que a receita das empresas regulamentadas de segurança privada no Brasil.

\section{INDETERMINAÇÃO DO CONTROLE SOCIAL}

A grande variedade de formas assumidas pela privatização do controle social e pela segurança privada no Brasil contribui para obscurecer o papel do Estado na geração da insegurança socialmente estruturada, assim como o seu fracasso para resolvê-la adequadamente.

O papel do Estado, nesse processo, é mais visível quando componentes da organização policial são privatizados, como no Rio de Janeiro, onde o governo estadual é pago para subcontratar grupos de policiais militares para proteger prédios governamentais, bem como instalações de empre-

${ }^{14}$ De acordo com Zapparolli et al. (1999), existem $150 \mathrm{mil}$ vigilantes regulamentados em São Paulo. O SESVESP registra apenas 100 mil para 1999, argumentando que pelo menos 20 mil vigilantes foram eliminados desde 1997, devido, principalmente, à substituição do trabalho humano por equipamentos de vigilância, uma forma crescente de controle social preventivo no Brasil. A diferença entre as estimativas, de 30 mil, é provavelmente devida à inclusão por Zapparolli (1999) de vigilantes privados não-regulamentados nos seus cálculos. 
sas e negócios privados. Tendo sido transformados em vigilantes, esses policiais militares em serviço fornecem proteção para instituições privadas ou prédios públicos em troca de equipamento (muitas vezes melhor do que o fornecido pelo Estado) e remuneração financeira (uma parte vai para a própria organização da Polícia Militar). Segundo o secretário de Segurança Pública do Rio, que trata desses contratos, esse sistema aporta cerca de 690.000 dólares mensais ou oito milhões de dólares para a Polícia Militar do estado (Folha, 1998b, p.4-5), contribuindo para preencher lacunas no orçamento dessa força policial. Isso sugere que as pressões para a privatização dos serviços policiais pode vir tanto da necessidade do governo de aumentar recursos limitados de controle social, quanto de demandas dos cidadãos por uma melhor segurança. Denunciando esse sistema de privatização do trabalho policial, ${ }^{15}$ a associação dos policiais militares subalternos do Rio e representantes das empresas de segurança privada salientam que uma porção crescente de policiais militares em serviço dedica-se ao policiamento particular e não-público, o que reduz o número de policiais disponíveis no Rio de Janeiro para o público em geral (1998b, p.4-5).

Um desvio cada vez mais comum e talvez ainda mais notório dos recursos da polícia configura-se quando policiais brasileiros na ativa criam e gerenciam suas próprias empresas de segurança. Além de violarem a maior parte da legislação estadual e municipal, tais empresas de segurança criam conflitos de interesses e lealdades entre o serviço público e o privado. Efetivamente, muitas empresas de segurança são gerenciadas a partir de repartições policiais. Por exemplo, o proprietário e gerente de uma das

${ }^{15}$ Essa subcontratação é comum também nos Estados Unidos. A cidade de Nova Iorque permite que seus policiais fardados possam trabalhar, quando fora de serviço, para clientes como Macy's, o Cirque du Soleil e o time de beisebol dos Yankees. O “maior cliente" da cidade, os Yankees, contratou pelo menos 28 policiais uniformizados de Nova Iorque de folga, em 1998, para trabalhar no estádio para jogos em casa (Lentz, 1998). Em Albany, policiais fora de serviço são pagos para trabalhar para o Departamento de Transportes do Estado de Nova Iorque (Gazeta de Schenectady, 2000, p.1, 4). Esses arranjos tornaram-se cada vez mais comuns na década de 1990. maiores empresas de segurança do estado de São Paulo, a Vanguarda Nacional, é um dos 11 policiais civis e um dos quatro policiais militares nesse estado que possuem e operam uma empresa de segurança privada. Isso coloca os donos das empresas de segurança privada e aqueles que trabalham para eles na posição contraditória de serem pagos para trabalhar na segurança pública e, ao mesmo tempo, ganharem dinheiro com seu esvaziamento. A contradição é ainda mais gritante quando se leva em conta que a atividade ou inatividade policial afetam o aumento do crime e a sensação de insegurança, os quais, por sua vez, podem estimular o crescimento das empresas de segurança privada. Como esses policiais se situam na fronteira jurisdicional entre o policiamento público e o privado, contratam seus próprios subordinados para trabalhar para eles nas folgas e até mesmo utilizam os carros e outros equipamentos da polícia em seus negócios (Folha, 1998a, p.3). Desse modo, ignoram por completo qualquer limite entre segurança pública e privada e os interesses potencialmente contraditórios dentro de cada esfera.

Enquanto as empresas regulamentadas de segurança, dentre as organizações de segurança operadas e gerenciadas por policiais, obscurecem a linha entre o policiamento público e o privado - seja desenvolvendo ambos, seja se dedicando, mesmo quando em serviço, exclusivamente ao policiamento privado -, as empresas de segurança clandestinas apagam completamente a distinção tanto entre tais modalidades de policiamento quanto entre elas e as ações de justiceiros e esquadrões da morte. Nessa linha, há muitos registros de vigilantes clandestinos que protegem abertamente interesses privados em detrimento do direito público. Enquanto impedem ameaças à propriedade privada e empresarial - a competência legalmente exigida da segurança privada -, muitos vigilantes se envolvem, de modo frequente, na aplicação da lei. Nesse processo, eles rompem a lei e a frágil membrana que os separa de membros de esquadrões da morte e justiceiros assassinos. 
Os "guardadores da rua" da cidade de São Paulo (Folha, 1999a, p.4-11) são um exemplo de vigilantes clandestinos que, rotineiramente, infringem esse limite. Contratados por particulares, residências ou empresas para vigiarem sua propriedade, os "guardadores da rua" geralmente têm a barba por fazer, vestem-se de qualquer jeito e usam coletes escuros com a palavra escrita "vigilante" a única característica que os diferencia da população que eles controlam. Eles têm uma grande autonomia de trabalho ao proteger as comunidades mais ricas de elementos supostamente ameaçadores: mendigos, bêbados, crianças de rua e "vagabundos". Não existem requisitos formais para tornar-se um "guardador da rua", e a maioria não tem carteira de trabalho válida ou qualquer treinamento. Em certo sentido, esses seguranças mal vestidos se parecem com as milícias privadas de fazendeiros do interior do Brasil. Seu modus operandi privatiza e individualiza o "inimigo", neutralizando uma pessoa de cada vez. No entanto, a fidelidade duradoura comumente dedicada pela milícia tradicional do interior àqueles a quem servem é enfraquecida ou substituída por relações financeiras transitórias entre os modernos "guardadores da rua" e seus empregadores. Sua lealdade é ditada pelo preço oferecido por seu trabalho, que varia de acordo com vários fatores: a disponibilidade desses trabalhadores, também influenciada pelo desemprego na indústria, as flutuações no medo do crime, que estimulam a demanda por serviços de segurança privada, e as necessidades e demandas particulares de cada cliente para determinados tipos de serviços de segurança.

Apesar da dificuldade de obter cifras exatas, tudo indica que um número significativo de "guardadores da rua" de São Paulo é formado por policiais fora de serviço, o que aponta novamente para a fluidez de limites entre polícia, segurança privada e "vigilantismo". Ao trabalhar na segurança privada, regulamentada ou clandestina, como "guardador da rua", o policial utiliza o seu tempo de folga para obter uma renda adicional e complementar o salário. Considerando que tur- nos de doze horas podem ser alternados com dias de folga, um vigilante clandestino, trabalhando como autônomo, pode ganhar entre 300 e 400 dólares americanos por mês (SESVESP, 2000; Folha, 1999a, p.4-11), o dobro do salário mensal de um soldado da Polícia Militar. Um dos resultados disso é que diminui a pressão sobre a polícia e o governo para melhorar os salários e, ao mesmo tempo, resolver o problema da insegurança socialmente estruturada.

Com as cidades e governos americanos sofrendo pressões semelhantes, forças de segurança, como os "guardadores da rua" de São Paulo, têm sido contratadas pelos Distritos de Melhoria de Negócios (sigla em inglês, BID) em Los Angeles e Nova Iorque, para expulsar "indesejáveis" de propriedades públicas e, portanto, tratando-as como um bem privado. Empresas de segurança associadas com os BIDs têm sido denunciadas por interrogar, tratar com violência, e até mesmo deter e encarcerar ilegalmente pessoas (Los Angeles Times, 1999, C1). A remoção dos "criminosos" potenciais do cenário urbano pelos vigilantes do BID é financiada por taxas pagas à administração pública por proprietários, comerciantes e negócios ligados ao BID. A cidade depois repassa parte desses valores para que o BID contrate policiamento privado. Essa parceria público-privada para garantir a "segurança" aos turistas, consumidores locais e comércio converte os espaços públicos em privados e mercantiliza a segurança pública.

Seja em Los Angeles, Nova Iorque ou São Paulo, à medida que um número crescente de espaços públicos torna-se propriedade, de fato, de proprietários privilegiados de apartamentos e de empreendimentos, a exemplo de shopping centers, essas áreas passam a ser definidas, declaradas e regulamentadas pela legislação e práticas comerciais. Dado que a vida pública se desenvolve cada vez mais em propriedades privadas de massa (Shearing; Stenning, 1983, p.496), a definição de "desvio" de comportamento dentro dessas áreas gira em torno da lógica específica da propriedade privada e do lucro. Com a 
"segurança" modelada sob medida para proteger esses espaços, os agentes de controle social mudam o seu foco "de descobrir e responsabilizar infratores para eliminar as fontes de ameaças no futuro" (1983, p.501). Nessa linha, em que espaços públicos urbanos relativamente heterogêneos são transformados em áreas privadas, homogêneas e simbolicamente cercadas, e os governos, sobrecarregados e fiscalmente tolhidos, transferem a responsabilidade de proteger e regulamentar esses espaços para a segurança privada, cria-se uma "nova categoria de 'infratores", a daqueles que representam ameaças materiais e simbólicas aos interesses do cliente (p.501). Esse controle social particular estimula a formação de áreas que se assemelham a "zonas de livre comércio" nos países em desenvolvimento, onde a indústria nacional e internacional recebem incentivos fiscais e políticos generosos de Estados nacionais para estabelecer ou expandir seus negócios. Dentro dessas áreas - quer sejam chamadas "zonas de livre comércio", ou, como é mais comum, simplesmente quarteirões urbanos e shopping centers - o comércio e a indústria são o governo, de fato. Shearing e Stenning (1983, p.503) rotulam isso de "novo feudalismo", caracterizando essas áreas como grandes extensões de propriedade e espaços públicos associados sob o policiamento de empresas privadas. Tais empresas desenvolvem aí um extenso aparato de segurança, do qual "o pessoal de segurança uniformizado é apenas a ponta visível do iceberg”. Consequentemente, desenvolve-se uma simbiose entre essas forças de segurança privada e as forças policiais do governo local, com efeitos repressivos modelados pelas definições de desvio fundadas no lucro e na mercantilização do controle social.

Em resumo, à medida que o Estado brasileiro sanciona, explicita e implicitamente, uma mistura privatizada de policiais fora de serviço e cidadãos comuns, empregados na segurança privada regulamentada ou clandestina, ele mascara seu papel oficial na promoção dos interesses privados e na ocultação das suas consequências violentas.

\section{PRIVATIZANDO E MERCANTILIZANDO O CONTROLESOCIAL}

O controle social privatizado é juridicamente definido pelas necessidades daqueles que pagam por ele, e não por qualquer ideia generalizada de bem-estar social ou mesmo por uma "ética" de mercado coletivo privatizado. Se os agentes pagos são leais a uma entidade privada, e não a interesses públicos coletivos ou privados generalizados, um cliente privado pode facilmente colaborar ou discordar de outro. Com o controle social privatizado, mercantilizado e definido instrumentalmente como qualquer atividade que promova os interesses dos seus compradores, o grau de "segurança" é ditado pelo caráter dos recursos privados e dos interesses dos consumidores a serem protegidos. Tal princípio gera uma dinâmica de controle social antecipatório, de gestão de risco, que "responde a tudo que [...] ameace a gama de interesses que operam dentro do mercado" (Shearing, 1996, p.291). No entanto, onde o comportamento das forças de segurança é ditado por exigências e medos do mercado e do consumidor, cada pessoa, grupo ou empresa pode facilmente definir os seus interesses à revelia dos interesses e direitos dos demais. A partir dessa concepção de controle social, em que "o policiamento parcial, e não imparcial, é necessário", ele se converte em uma mercadoria que "não só pode como deve ser comprada e vendida no mercado" (1996, p.291292). No Brasil, isso acontece com a subcontratação de policiais e vigilantes regulamentados para antecipar e gerir os riscos de segurança para empresas e agências governamentais, bem como de vigilantes, regulamentados ou não, para dar segurança a pequenos comerciantes e moradores, e de esquadrões da morte e justiceiros para "limpeza" de favelas.

A experiência do Brasil com a privatização do controle social não pode ser descartada como atípica. Shearing (1996) observa que, mesmo nos sistemas modernos e altamente racionalizados de controle social da Europa e dos Estados Unidos, "o policiamento tem se tornado [...] cada 
vez mais fraturado, embutido e descentralizado", resultando na descentralização tanto dos mecanismos de controle central quanto dos próprios loci de controle. Isso criou conjuntos "subpolíticos" ou nódulos de autoridade localizada "que existem dentro de um espaço jurídico e político que nem é puramente público (ordenado pelo Estado), nem (puramente) privado" (1996, p.285-286). Em meio a cada uma dessas redes de autoridade localizada, cada sistema privatizado contém seu próprio locus de autoridade, criado, no caso de empresas de segurança, para proteger a sua participação nesse mercado e, de forma associada, para resguardar as necessidades de cada cliente. Alianças entre sistemas de controle social públicos e privados também criam loci de autoridade, com a polícia muitas vezes sendo usada como suporte da segurança privada. Davis (1992, p.250-251) argumenta que, em Los Angeles, essa "divisão social do trabalho entre os serviços de policiamento público e privados" envolve os primeiros como suportes necessários para os últimos: enquanto a segurança privada captura as atividades que exigem mais mão de obra, a polícia se entrincheira na supervisão de macrossistemas de segurança de alta tecnologia no estilo “Robocop”. No entanto, o que Davis não consegue apreciar é a função simbólica de cada uma dessas modalidades em uma divisão do trabalho em que "[atores] estatais e não-estatais procuram gerir um ao outro [...] para produzir os efeitos que eles consideram como desejáveis” (Shearing, 1996, p.287). Isso envolve reduzir os conflitos potencialmente perturbadores entre interesses privados e entre eles e o governo, enquanto esse último promove uma imagem de sua capacidade de manter a hegemonia sobre o controle social. Por exemplo, as equipes da Polícia Militar que "atiram para matar" nas favelas das grandes cidades do Brasil talvez estejam cumprindo a função simbólica de mostrar ao público e à indústria de segurança privada, numericamente dominante e melhor financiada, que o Estado ainda controla, apesar de tudo, a segurança pública.
Sublinhando outro aspecto simbólico importante da interface entre o policiamento público e a segurança privada, Loader (1999) argumenta que, dentro de um "mercado de segurança” que inclui ambos os sistemas, o próprio ato de "consumir" uma forma de policiamento em vez de outra reforça a hierarquia social e política. Ou seja, a "escolha" do consumidor pela segurança privada em lugar do policiamento público é vista como uma seleção feita por consumidores "melhores" (ou seja, consumidores de status mais elevado, mais ricos, pagantes), que usam seu "poder de compra" para assumir o controle de seus espaços sociais. Em contraste com isso, o sistema de controle social público é utilizado por “"consumidores defeituosos', que (considera-se) não querem ou não podem ser seduzidos pelo mercado" (1999, p.384). Dado que “as mercadorias operam como um meio de expressão de identidade e significam o lugar de cada um dentro das hierarquias sociais vigentes", os bens e serviços adquiridos evidenciam a posição social das pessoas e mantêm as diferenças entre as posições relativas dos diferentes atores. Assim, as pessoas operam dentro dos mercados de segurança e, entre eles, elas são socialmente marcadas seja como "bons consumidores" - que controlam as suas vidas por intermédio da segurança privada - ou "consumidores defeituosos" que, precisando da polícia, não podem "escapar da arregimentação de necessidades" associada com a "uniformidade cinzenta do policiamento público” (p.383). Em suma, o “consumo” de controle social é, mais do que nunca, um marcador social simbólico: "Ao serem oferecidos, aceitos, comprados, ou recusados, [estes] recursos podem reforçar ou enfraquecer os limites [sociais] existentes” (Loader, 1999, p.381).

\section{TRANFERÊNCIA DO CONTROLE SOCIAL}

Mesmo que o consumo diferencial de recursos de controle social reforce e estabilize as hierarquias sociais pela diferenciação entre "ou- 
tros perigosos" e "verdadeiros cidadãos", essa relação entre policiamento público e controle social privatizado pode desestabilizar o próprio sistema que ela deve sustentar. Efetivamente, o que acontecerá quando o governo, dentro de um sistema mercantilizado de controle social privatizado, não puder mais manter a ficção de que controla a segurança pública? Quando as empresas de segurança privada decidirem controlar as empresas clientes que as contratam? Ou quando o "esquema de proteção" das próprias empresas de segurança, em conluio com a polícia, for tomado pelos agentes privados contratados para proteger e fazer respeitar uma paz mercantilizada? Essa devolução pode ocorrer quando diferentes partes do sistema de controle social começarem a atacar umas às outras e se afastarem, de uma vez por todas, do controle centralizado. Naturalmente, não há garantias de que, sob o peso das contradições inerentes a uma situação onde o governo ora se alinha ora se dissocia da segurança privada, os componentes privatizados do sistema agirão sempre no interesse de seu empregador privado imediato em lugar do interesse das empresas de segurança que os empregam. Também não há garantias de que grupos policiais não entrarão em conflito com o sistema de controle social do Estado, ou uns com os outros (já que protegem empresas ou residências com diferentes potenciais econômicos ou que competem por recursos), ou de que, por fim, eles não se tornarão agentes "livres" de controle social, agindo para benefício próprio, extorquindo dinheiro de proteção e recursos daqueles que os contrataram para resguardar.

Muitos governos nacionais e locais aparentemente se dispuseram a correr esses riscos pelos benefícios positivos de curto prazo decorrentes da privatização do controle social (Tilly, 1985). As vantagens de curto prazo da segurança privada foram particularmente atrativas para Estados politicamente precários e fiscalmente tolhidos de países em desenvolvimento. Por meio dela ou de algumas de suas modalidades, os Estados podem implementar políticas violentas de controle social sem serem responsabilizados por isso. Nessa linha, ao descentralizar o policiamento por meio da criação de "subcentros de autoridade" e da imagem de "ação à distância" (Shearing, 1996, p.287-288), os governos podem reduzir os custos políticos e econômicos de seus objetivos repressivos. Além disso, a mercantilização do controle social desloca a atenção nacional e internacional da violência estatal e do papel do Estado na proteção de interesses particulares, fazendo com que a violência seja vista como algo aleatório, sem planejamento e não-oficial.

Esses governos caminham em uma linha politicamente perigosa. Se o Estado canaliza e dá forma à violência extralegal para apoiar os seus interesses, ele deve manter alguma ligação com agentes de segurança privada parcialmente competitivos. Para disfarçar a natureza parcial de classe desse controle social, o Estado deve manter certa distância da segurança privatizada. No entanto, quanto maior essa distância, maior será a semelhança do Estado nacional com a posição do feiticeiro que perdeu o controle sobre os poderes infernais invocados por seus feitiços (Marx; Engels, 1985). O Estado perde, no processo, o seu monopólio sobre o controle social armado em seu próprio território. Como advertem Shearing e Stenning (1983, p.504), "o desenvolvimento da segurança privada moderna levanta a possibilidade de transferir a soberania do Estado diretamente para empresas privadas, tanto nas suas versões nacionais quanto, mais significativamente, nas internacionais.

Por essas razões, vale reafirmar que dois processos aparentemente opostos têm operado em conjunto no Brasil. O primeiro de centralização (e retomada) do controle estatal sobre a segurança interna. O segundo, e simultâneo ao anterior, de descentralização do controle social mediante a concessão e perda parcial de hegemonia do Estado sobre a segurança interna, para organizações e grupos de segurança privada. Essas pressões contraditórias têm contribuído para uma simbiose funcional entre tendências centralizadoras e privatizantes. O policiamento 
privatizado realiza, a partir do seu estatuto social e politicamente indeterminado, o trabalho sujo que um Estado democrático não pode fazer oficialmente, caso deseje ser considerado como tal. No final das contas, a relativa invisibilidade institucional do policiamento privatizado o torna um complemento perfeito para o policiamento público fracassado.

A parceria simbiótica e invisível entre o controle social privatizado e seu equivalente, técnico e "profissionalizado" controlado pelo Estado tem importantes implicações para o funcionamento democrático, o presente e o futuro das instituições de controle social. Deixando de lado a obviedade de que a militarização centralizada do policiamento e a guerra contra grandes segmentos da população anulam a democracia, Loader (1999, p.384) aponta que o mercado de segurança privada oferece "uma fuga institucionalizada" dos requisitos "democráticos" que acompanham a disputa pelos serviços policiais. Nessa linha, esse mercado permite que seus clientes "busquem seus requisitos de segurança particularistas (e autodefinidos), sem referência a qualquer concepção do bem comum, e livre das obrigações associadas à prática da cidadania democrática." Como clientes de um serviço, os usuários da segurança privada se definem como “compradores" e não como cidadãos que procuram usar a sua 'voz"' (1999, p.384) para influenciar na distribuição, qualidade e equidade dos serviços policiais.

Por conseguinte, a privatização da segurança interna inevitavelmente força a nova democracia no Brasil a navegar um curso traiçoeiro entre o Cila da violência da polícia, burocraticamente impessoal, custosa e diretamente supervisionada pelo Estado e o Caríbdes dos vigilantes, esquadrões da morte e justiceiros assassinos, não-oficiais e apenas indiretamente controlados pelo Estado.

(Recebido para publicação em junho de 2010) (Aceito em agsto de 2010)

\section{REFERÊNCIAS}

BAYLEY, David; SHEARING, Clifford D. The future of policing. Law and Society Review, [S.l.], v.30, n.3, p.585606, 1996.

BUREAU OF JUSTICE STATISTICS (BJS). Homicide trends in the U.S., 1950-1998. 2000. Disponível em: www.ojp.usdoj.gov/bjs/homicide/hmrt.htm.

BUVINIC, Mayra; MORRISON, Andrew; SHIFTER, Michael. Violence in Latin America and the Caribbean: a framework for action. Disponível em: www.iadb.org/sds/utility.cfm/173/ ENGLISH/pub/515. Acesso em: march, 1999.

CALDEIRA, Teresa Pires do. City of walls: crime, segregation, and citizenship in São Paulo. 1992. Dissertation, (PHD) - University of California. Berkeley, 1992.

CANO, Ignacio. The use of lethal force by police in Rio de Janeiro. Policing in Democratic Societies, Vienna, v.6, n.1, nov. 1997

CARDIA, Nancy. Primeira pesquisa sobre atitudes, normas culturais e valores em relacao a violencia em 10 capitais brasileiras. Brasilia: Ministerio da Justica. Secretaria de Estado dos Direitos Humanos, 1999.

CENTERS FOR DISEASE CONTROL (CDC) Youth violence in the United States. Youth violence facts - National Center for Injury Prevention and Control. 2000 Disponível em: www.cdc.gov.

CHEVIGNY, Paul. Edge of the Knife: police violence in the Americas. New York: New Press, 1996.

COOPER, Steven H. Stand: contending ideas and opinions. Bellevue: Coursewise Publishing, 2000.

DAVIS, Mike. City of quartz. New York: Random House Economist, 1992

ESTADO DE SÃO PAULO. Risco de morte no Morumbi e 18 vezes maior que nos Jardins. São Paulo, 11 dez. p.4 1997.

FOLHA DE SÃO PAULO. Comércio contrata 'zeladores de rua' para expulsar mendigo de área pública. São Paulo, 27 set. p.4-11, 1999a.

$1,8 \%$ dos cidadãos concentram $51 \%$ dos homicídios. São Paulo, 17 out. p.3, 1999b

Morar sem infra-estrutura aumenta risco de ser morto. São Paulo, 03 nov. p.3-9, 1999c.

Ouvidoria tem mais denuncia de mortes. São Paulo, 10 out. p.3-4, 1999d.

PM fardado mata $63 \%$ a mais que em 98 ; número de policiais mortos cresce $200 \%$. São Paulo, 20 out. p.3-11. $1999 \mathrm{e}$

. Rio premia policial que reduz violência. São Pauo, 20 out. p.3-6, $1999 f$. $\overline{\text { p.3, } 1998^{\mathrm{a}} \text {. }}$

Vigilantes superam as policiais. São Paulo, 08 fev.

PM do Rio privatiza serviços de segurança. São Paulo, 12 p.4-5, 1998b.

Vitoria e a cidade mais perigosa para jovens. São Paulo, 10 dez. p.3, 1998c.

Policia de RJ mata 5 vezes mais que a de SP. São Paulo, 13 dez. p.3-11, 1998d.

GAZETA DE SCHENECTADY. Police DOT ink contract. [S.l.], apr. 10, p.B-1, 4, 2000.

HUGGINS, Martha K. Modernity and devolution: the making of police death squads in modern Brazil. In: CAMPBELL, 
Bruce B.; BRENNER, Arthur D. (Ed.) Death squads in global perspective: murder with deniability. New York: St. Martin's Press, 2000.

. Scapegoating outsiders: the murders of street youth in modem Brazil. Policing and Society, n. 5, p. 265-280, 1995

; MESQUITA, Myriam. Vigilantism and the state in modern Latin America. New York: Praeger, 1991.

\section{INTERNET SITES}

www.cdc.gov (Centers for Disease Control web site).

www.iabd.org

www.ojp.usdoj.gov/bjs/homicide/race.htm (Bureau of Justice Statistics).

www.usdoj.gov:80/bjws/pub/pdf/tjv97up.pdf (U.S. Department of Justice Statistics).

JOHNSON, Kevin. Millennium anxieties put security companies in demand. USA Today [S.l.], jan 04, p.4-A, 2000.

JORNAL DO BRASIL Ligue 234-2010 e denuncie o esquadrão da morte. Rio de Janeiro, 28 set. 1975.

KOCIENIEWSKI, David. Police's use of deadly force in New York is low for nation. Times, New York, jan. 01, p.B-1, 1998.

LANGGUTH, A.J. Hidden terrors. New York: Pantheon. 1978.

LEEN, Jeff; CRAVEN, Jo; JACKSON, David; HORWITZ, Sari. District Police Lead Nation in Shootings. Washington Post, nov. 15 p.A-1, 1998

LENTZ, Philip. Program at NYPD is a hit with business owners. Crains New York Business, New York, may. 04, p.14, 1998.

LOADER, Ian. Consumer culture and the commodification of policing and security. Sociology, [S.l.], v. 33, n.2, p.373392, 1999.

LOS ANGELES TIMES (LAT). Suit challenges private security patrols. Los Angeles, nov. 17 p.C-1, 1999.

MARX, Karl; ENGELS Friedrich. The communist manifesto. Bergenfield, NJ: Penguin, 1985.

NEW YORK TIMES (NYT). Despite Diallo, data show gun restraint. New York, Feb. 4, 2000.
NEV. Núcleo de Estudos da Violência. Número de homicídios e taxa por 100 mil habitantes, segundo as capitais - Brasil 1991-1997. NBV, University of Sao Paulo, Feb. 14, 2000.

REUTERS WORLD SERVICE. Brazil worst for police violence in Americas. Rio de Janeiro: Lexis-nexis.com/ universe/docu., 1997.

SCENES of police brutality and assassination shock country. [S.l.], n.268, apr., 1997.

SCHEPER-HUGHES, Nancy; HOFFMAN, Daniel. Kids Out of Place. NACLA v.27, n.6, 1994.

SCHORR, Daniel. America's fear industry. The Christian Science Monitor, aug. 20, p.11, 1999.

SEJUP. Serviço Brasileiro de Justiça e Paz. Disponível em: www.oneworld. org/sejup/269.htm

SESVESP. Sindicato das Empresas de Segurança Privada. Private security report. São Paulo: 2000.

SHEARING, Clifford D. Reinventing policing: policing as governance. In: MARENIN, Otwin (Ed.) Policing change, changing police: international perspectives. New York: Garland, 1996.

; STENNING, Philip C. Private security: implications for social control. Social Problems, [S.l.], v.30, n.5, p.493$506,1983$.

TILLY, Charles. War making and state making as organized crime. In: EVANS, Peter et al. (Ed.) Bringing the state back in. New York: Cambridge University Press, 1985.

TIME MAGAZINE. The death squads of Rio. Apr. 25, p.61, 1969.

UNIFORM CRIME REPORTS (UCR). Uniform crime reports of the federal bureau of investigation, Bureau of Justice Statistics. Washington, D.C.: U.S. Government Printing Office, 1997.

U.S. DEPARTMENT OF STATE. Human rights reports. Washington, D.C.: U.S. Government Printing Office, 1999.

VEJA. Justica e feita. jul. 29, p.31, 1970a O esquadrão da morte. mar. 25, 1970b.

ZAPPAROLLI, A.; SCHIVARTCHE, F. Seguranca, S.A. Veja, out. 6, p.12-17, 1999. 


\section{URBAN VIOLENCE AND POLICE PRIVATIZATION IN BRAZIL: blended invisibility}

\section{Martha K. Huggins}

This article argues that much police violence the world over, focusing specifically on Brazil, is becoming increasingly invisible in spite of the very public nature of police homicides. Ideologies about race and criminality hide killings of Blacks under the belief that these murders are in response to some groups 'greater criminality'. Police organization-particularly militarized assaults on favelas-frame such violence as a 'war against crime' where criminals out number 'good' police and citizens. The continuing blending of 'formal' and 'private' policing makes it difficult to determine which social control entity carried out a citizen murder, especially given the participation of on- and offduty police in 'private' police duty. In the process, "security" has developed as a commodity that distinguishes the poor from the rich and separates criminals from non-criminals-those who must rely on formal police for 'security', the poor, are perceived as criminals to be controlled; those who can purchase private security, the wealthier, use private police to protect them against those victimized by public security.

KEY words: police violence, police trends, militarization, privatization, state control crisis.

\section{VIOLENCE URBAINE ET PRIVATISATION DES SERVICES DE POLICE AU BRESIL: un mélange invisible}

\section{Martha K. Huggins}

Cet article affirme qu'une grande partie de la violence policière dans le monde, en particulier au Brésil, est devenue invisible malgré le caractère public des meurtres policiers. Les idéologies concernant la race et la criminalité cachent l'assassinat de pauvres et de Noirs, justifié en disant qu'il s'agit d'une réponse à la criminalité qui a augmenté au sein de certains groupes de population. Les services de police, au cours d'opérations militaires dans les favelas, caractérisent cette violence comme une "guerre contre le crime" dans laquelle les délinquants sont plus nombreux et armés que les "bons" policiers et les citoyens. Le mélange entre police publique et police privée ne permet pas de déterminer laquelle de ces entités de contrôle social entraine tous ces assassinats, notamment en raison de la participation de policiers en service et en dehors de leurs heures de service dans des sociétés privées de sécurité. Vu ce processus, la sécurité est devenue une marchandise qui sépare les pauvres des riches et les criminels des noncriminels. Bien que les pauvres aient besoin des services de police plus que les riches, ils sont perçus comme faisant partie des classes sociales dangereuses et qu'il faut contrôler. À leur tour, les riches qui peuvent payer une sécurité privée, s'en servent pour se protéger de ceux qui sont victimes de la sécurité publique.

Mots-CLÉs: violence policière, tendances des services de police, centralisation, privatisation, crise du contrôle de l'état.

Martha K. Huggins - Professora Titular no Departamento de Sociologia da Tulane University, New Orleans, LA. É uma "brasilianista", professora de Teoria Social, Sociedade Brasileira, Etnografia do crime e outras temáticas. Suas pesquisas tratam de crime e controle social, tortura e assassinatos. É autora de sete livros, tendo publicado dois no Brasil e nos Estados Unidos: Trabalhadores de Violencia (Brasília: Ed. UnB, 2005) e Policia e Politica (São Paulo: Cortez, 1998). Dentre as publicações mais recentes destaca-se "Qualitative Research in Criminology: Negotiating Field Challenges”, International Handbook of Criminology, Shoham, Knepper, Kett. (Eds.)(Routledge Forthcoming, 2010). 